\title{
Communicable disease surveillance: Strengthening the national perspective
}

\author{
PAUL N SOCKETT PhD
}

$\mathrm{T}$ he mass vaccination campaigns in Canada, in response to an increase in group $C$ meningococcal meningitis in 1991-93 and the world reaction to plague in India in 1994 , were salutory reminders of the ability of infectious diseases to provoke widespread public and political concern. Communicable diseases remain the major cause of morbidity in the world and are a leading cause of mortality in developing nations. However, the declining incidence of many of these diseases in Canada and other developed nations, allied to improvements in social conditions, population health status and childhood immunization practices, and the advent of antibiotics, has created high public and political expectations concerning our ability to control communicable disease. Success has been achieved in substantially reducing morbidity and mortality due to such childhood diseases as measles, diphtheria, polio, pertussis and mumps. Such success stories are, however, countered by the persistence of sexually transmitted diseases, as the most common reportable diseases in Canada (1), and respiratory virus and enteric infections, as major causes of morbidity, in addition to the emergence of 'new' infections such as AIDS and multiple antibiotic-resistant microorganisms including, for example, multiple drugresistant tuberculosis.

Disease Surveillance Division, Bureau of Communicable Disease Epidemiology, Laboratory Centre for Disease Control, Ottawa, Ontario

Correspondence and reprints: Dr P Sockett, Chief, Disease Surveillance Division, Bureau of Communicable Disease Epidemiology, 2nd Floor, LCDC Building, Tunney's Pasture, Ottawa, Ontario K1A OL2. Telephone 613-941-1288,

Fax 613-998-6413, e-mail psockett@hpb.hwc.ca

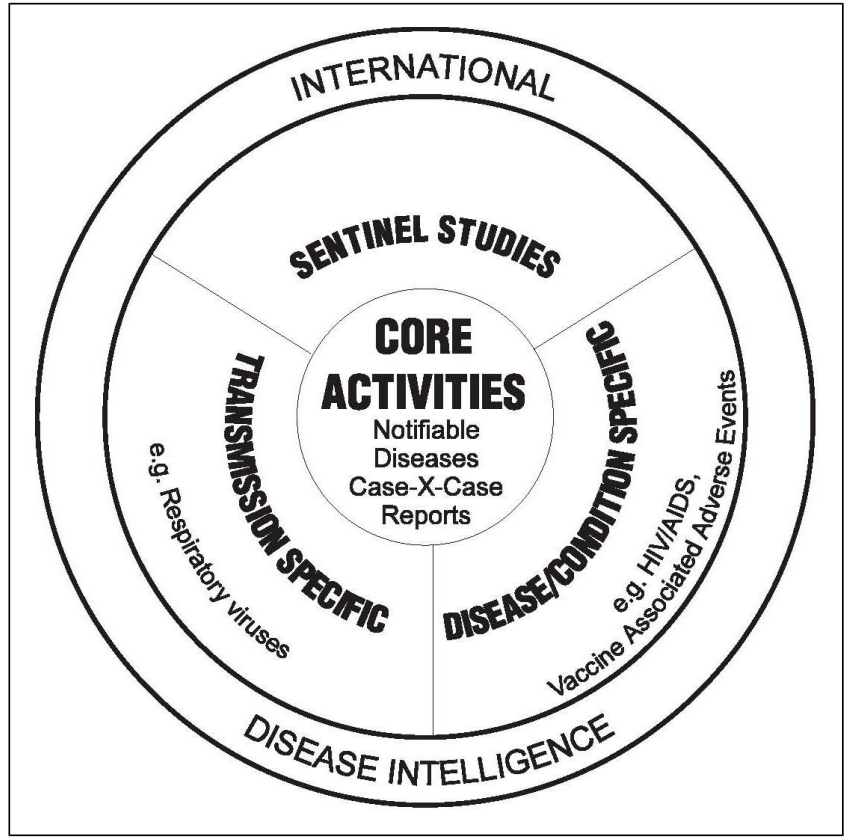

Figure 1) Levels of infectious disease surveillance in Canada

Control of communicable diseases requires effective mechanisms for detecting as early as possible the presence, or monitoring the absence, of infections in the population; for providing up to date relevant information on disease trends to health professionals; and for preventing, controlling and treating specific diseases. Surveillance data are useful at two distinct levels. At the first level, usually local, such information should be able to identify changes in trends which, when nec- 
TABLE 1

National notifiable diseases

\begin{tabular}{ll}
\hline AIDS & Meningitis, pneumococcal \\
Amoebiasis & Meningitis, other bacterial \\
Botulism & Meningitis, viral \\
Brucellosis & Meningococcal infections \\
Campylobacteriosis & Mumps \\
Chancroid & Paratyphoid \\
Chickenpox & Pertussis \\
Chlamydia, genital & Plague \\
Cholera & Poliomyelitis \\
Diphtheria & Rabies \\
Giardiasis & Rubella \\
Gonococcal infections & Rubella, congenital \\
Gonococcal ophthalmia & Salmonellosis \\
neonatorum & Shigellosis \\
Haemophilus influenzae B & Syphilis, congenital \\
Hepatitis A & Syphilis, early latent \\
Hepatitis B & Syphilis, early symptomatic \\
Hepatitis C & Syphilis, other \\
Hepatitis non-A, non-B & Tetanus \\
Legionellosis & Trichinosis \\
Leprosy & Tuberculosis \\
Listeriosis & Typhoid \\
Malaria & Verotoxigenic Escherichia coli \\
Measles & Yellow fever \\
\hline & \\
\hline
\end{tabular}

essary, can be used to trigger action to control a problem. At the second level, usually that of provincial, territorial or federal governments, accurate information should contribute to policy making and the planning of care, prevention and control programs.

\section{COMMUNICABLE DISEASE SURVEILLANCE IN CANADA}

The mechanisms for the collection of surveillance data relating to communicable diseases by the Laboratory Centre for Disease Control (LCDC) currently take place at three levels (Figure 1). Central to these activities is the collection of aggregate data for the 47 notifiable diseases (Table 1). Each jurisdiction has public health legislation relating to the reporting of specific diseases to public health authorities, and the list of notifiable diseases varies with jurisdiction (2). There is no statutory requirement for reporting at the federal level; however, a list of 'nationally' reported diseases is produced by consensus agreement among provincial and federal health authorities through the Advisory Committee on Epidemiology (3). Aggregated age and sex data for each disease are transmitted monthly by most provinces and territories to the Bureau of Communicable Disease Epidemiology at LCDC. These data are tabulated quarterly in the Canada Communicable Disease Report (CCDR) and published in an annual summary as a supplement to the CCDR. In addition to the aggregated data some provinces also report more detailed information by case.

Complementary surveillance activities have developed
TABLE 2

Routine information output

\begin{tabular}{ll}
\hline \multicolumn{1}{c}{$\begin{array}{c}\text { Published } \\
\text { CCDR (available by Faxlink and BBS) } \\
\text { CCDR supplements }\end{array}$} & $\begin{array}{l}\text { Bi-monthly } \\
\text { Occasionally/ } \\
\text { annually } \\
\text { Measles Update }\end{array}$ \\
$\begin{array}{ll}\text { AIDS Update } \\
\text { Unpublished }\end{array}$ \\
$\begin{array}{ll}\text { Respiratory Virus Surveillance Report } \\
\text { News Brief }\end{array}$ & $\begin{array}{l}\text { Weekly } \\
\text { Weekly }\end{array}$ \\
\hline BBS Bulletin board system; CCDR Canada Communicable Disease Report
\end{tabular}

BBS Bulletin board system; CCDR Canada Communicable Disease Report

around these 'core' activities to collect more timely information or population-based statistics on specific diseases or groups of diseases. Sentinel surveillance is currently based on Immunization Monitoring Program ACTive (IMPACT) and the Sentinel Health Unit Surveillance System (SHUSS). IMPACT is a hospital-based system for monitoring immunizationassociated adverse events and other conditions including, at present, Haemophilus influenzae group b infection, congenital rubella syndrome, polio, infantile spasm and acute flaccid paralysis. SHUSS is based on nine health units in eight provinces and was created to carry out targeted surveillance within a defined population base. SHuss was described recently by Anderson (4).

Disease-specific activities are aimed, for example, at national surveillance of AIDS and the surveillance of human immunodeficiency virus-infected individuals in some provinces. Transmission-specific surveillance is aimed at nosocomial infections (5) and respiratory virus infections. The latter relies on the use of an interactive voice response system. By this mechanism provincial laboratories report weekly, during the winter, the numbers of specimens examined for influenza, respiratory syncytial, parainfluenza and some adenoviruses, and the number that are positive. This system permits the timely collection of data indicating respiratory virus activity. The outer ring in Figure 1 relates to the monitoring of reports from the World Health Organization (WHO) and individual countries to identify specific disease issues, which may be of interest to Canada.

Other major disease databases include data collected by Statistics Canada (eg, on tuberculosis) and hospital discharge data collected by the Canadian Institute for Health Information. However, the usefulness of data from these sources for the purposes of national surveillance of communicable diseases, in terms of timeliness, is more limited.

A variety of mechanisms are used for the dissemination of information based on data received by LCDC. These include both electronic and paper output. The current, routine output is listed in Table 2 and includes the twice monthly CCDR, which is available in both printed format and electronically via a Faxlink service and a bulletin board system (6). In addition to the regular CCDR, occasional and annual supplements relating to specific issues or tabulating national aggregated data are 
published; the most recent of these included the proceedings of the expert working group meeting on emerging infectious diseases, which met at Lac Tremblant (7), and the Notifiable Diseases Annual Summary for 1993. Other published reports include the quarterly Measles Update and the Quarterly AIDS Update. Regular unpublished reports to special interest groups include a weekly summary of national and international communicable disease issues and a weekly surveillance report on respiratory virus infections.

\section{DEVELOPING THE NATIONAL PERSPECTIVE}

The main justification for collecting data at the national level is to use such information to develop national policies and programs and to provide advice aimed at improving public health through legislation and prevention and control programs while making the most effective use of resources. Thus, the use of surveillance data can fall under one or more of the following areas.

Identification and control of potentially serious and epidemic disease: Surveillance activities may identify unusual events, such as the re-emergence of old pathogens or occurrence of newly recognized or unusual pathogens, or include programs designed to give early warning of common disease such as influenza. In this particular example, surveillance programs may need to include activities designed to collect both routine disease-specific (laboratory) data as well as other indicators of disease activity (eg, physician consultations, sickness absence records, pneumonia deaths). Programs involving surveillance of diseases with seasonal or periodic patterns of incidence lend themselves to innovative approaches to monitoring and analysis. These include the use of predictive modelling and disease mapping techniques.

Development and implementation of national prevention and control activities: National disease surveillance has a great deal to offer to programs related to the identification of risk factors and to the development of health education and immunization programs. This is both in terms of justification, including economic assessment of the costs and benefits of such programs, and the selection of diseases and populations for targeting.

Monitoring and assessment of national prevention and control activities: Disease surveillance activities are essential to prevention and control activities as one approach to evaluating the success, or otherwise, of a program or assessing its progress. Careful monitoring will facilitate targeting and refining of national programs, and could reduce costs by allowing resources to be concentrated and directed towards specific needs.

Publication of statistics to aid local, national and international priority setting: Central data collection carries a responsibility to ensure that the data are useful and available. These data should provide information about the impact of disease on the community and contribute to the development of decision making strategies. This process involves functional responsibility at several levels, although the boundaries need not be rigid. Generally, the collection of raw data and the implementation of control activities tend to be local responsibili-
TABLE 3

Examples of potential biases

\begin{tabular}{l} 
Quantitative bias \\
- Under-reporting \\
- Inconsistent reporting \\
- Case carry-over \\
Qualitative bias \\
- Variation in case definition \\
- Uniformity of dataset \\
\hline
\end{tabular}

ties, while the production of information and the development of policy are central functions and may occur in Canada at the level of provincial and federal government. Where global programs are involved, there may be interaction with international agencies in providing national data and in implementing and monitoring global targets.

The timeliness and quality of information output is highly dependent on the timeliness and quality of the data received. Quality here includes validity, the relationship of the sample to the population as a whole, the comprehensiveness of the dataset in relation to the population represented and the uniformity of the dataset in terms of the information collected. This raises issues about the variation among provinces over what is reported, when it is reported and the frequency of reporting. Such variation may reflect real differences in disease incidence and/or biases introduced into the datasets; these may be both quantitative and qualitative (Table 3). Although it is desirable to remove as many areas of bias as possible, from a practical viewpoint it may be of greater importance to be aware of what biases are there and how they influence the data.

Contribution to the international surveillance of disease: As an active member of the world public health community, Canada endeavours to support the global surveillance activities of agencies such as the WHO. Among others, responsibilities include providing these agencies with data on various diseases. Examples of this include contribution to the wHO surveillance of AIDS and influenza and participation in the Pan American Health Organization measles elimination program. Canada also made an important contribution to the WHO response to the plague epidemic in India in 1994. Through the use of ongoing operational information networks Canada was able to assist in the collation, analysis and dissemination of key information to national and international response centres.

\section{ISSUES THAT WILL INFLUENCE DEVELOPMENT OF COMMUNICABLE DISEASE SURVEILLANCE}

A number of issues related to the social, physical and biological environments in which we live can affect disease prevalence and incidence in the community, the likelihood of exposure to new or unusual pathogens and our ability to respond to or treat infection.

Some of the most important issues are listed in Table 4 and illustrate the diversity of these factors. Changes in the so- 
TABLE 4

Issues affecting development of infectious disease surveillance

- Social and demographic change

- Increased international contact resulting in an increased potential for introduction of exotic diseases

- Environmental change

- Emerging and re-emerging pathogens

- Drug resistance

cial environment, for example, will include such determinants as changes in population size and structure, individual and national wealth, and social abuse including injection drug use, alcoholism and smoking. For example, the population of Canada has doubled from 14.0 million in 1951 to 28.7 million in 1991. More important, however, was the increase in the age of the population over this period. While the proportion of people aged under 15 years declined from $30 \%$ to $20 \%$, the proportion of people aged 60 years and over increased from $12 \%$ to $16 \%$ and is likely to continue to increase $(8,9)$. The inevitable consequence will be an increasingly older population with a growing number of elderly people subject to failing health. Social and demographic factors may also include increased international contact resulting from greater numbers of Canadians travelling abroad and to more exotic locations, and increased immigration to Canada from tropical areas $(10,11)$.

The results of environmental change may be more difficult to predict but could include the effects of pollutants on health status and increasing contact between individuals and rare animal or insect-borne pathogens. Changes to the biological environment may result in increased exposure to new or reemerging pathogens, or to pathogenic microorganisms that have developed multiple drug resistance, as well as the risk of opportunistic infections in patients with depressed immune systems.

\section{SUMMARY}

The value of surveillance is easily underestimated when diseases are declining. Berkelman et al (12), writing about the American experience, recently gave a timely warning that "False perceptions that such threats had dwindled or disappeared led to complacency and decreased vigilance regard- ing infectious diseases, resulting in a weakening of surveillance - the foundation for control of infectious diseases." In Canada the current strengthening of federal infectious disease surveillance mechanisms through investment must enable data to be collected that are both more timely and representative of the population, provide timely and appropriate analysis to health professionals and policy makers, produce information that is relevant and accessible, and be versatile enough to react to changing needs. To achieve this requires not only appropriate resources but also a high degree of consensus among the major interest groups, both professional and consumer, as to what information is collected, the mechanisms employed to collect it and the use made of it. In this respect $L C D C$ has a responsibility to provide both the environment to encourage consensus and to follow through in the development and maintenance of appropriate programs.

\section{REFERENCES}

1. Gully PR, Peeling RW. Control of genital chlamydial infection. Can J Infect Dis 1994;5:137-9.

2. Carter AO. Notifiable diseases in Canada. Can Med Assoc J 1988;139:645-8.

3. Carter AO. Setting priorities: the Canadian experience in communicable disease surveillance. MMWR 1992;41(Suppl):79-94.

4. Anderson C. Sentinel health unit surveillance system. Can J Infect Dis 1994;5:207-9.

5. Paton S. Nosocomial infection program. Can J Infect Dis 1995;6:73-5

6. Paulson EJ. Dissemination of timely national public health information. Can J Infect Dis 1992;3:268.

7. Expert Working Group on Emerging Infectious Disease Issues. Proceedings and recommendations of the expert working group on emerging infectious disease issues. Can Commun Dis Rep 1994;Dec:20S2.

8. Leacy FH, ed. Historical Statistics of Canada, 2nd edn. Ottawa: Statistics Canada, 1983:A78.

9. Law B, ed. 1995 Corpus Almanac and Canadian Sourcebook 30th edn. Don Mills: Southam Inc, 1994:5.9.

10. Oderkirk J. Canadians travelling abroad. Can Social Trends 1991;22:2-7.

11. Statistics Canada. Canada Year Book. Ottawa: Statistics Canada, 1994:84-5.

12. Berkelman RL, Bryan RT, Osterholm MT, LeDuc JW, Hughes $\mathrm{JM}$. Infectious disease surveillance: a crumbling foundation. Science 1994;264:368-70. 


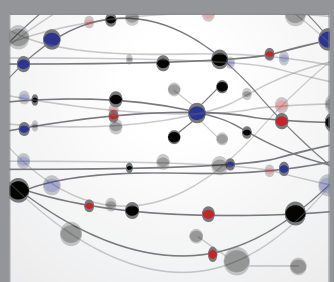

The Scientific World Journal
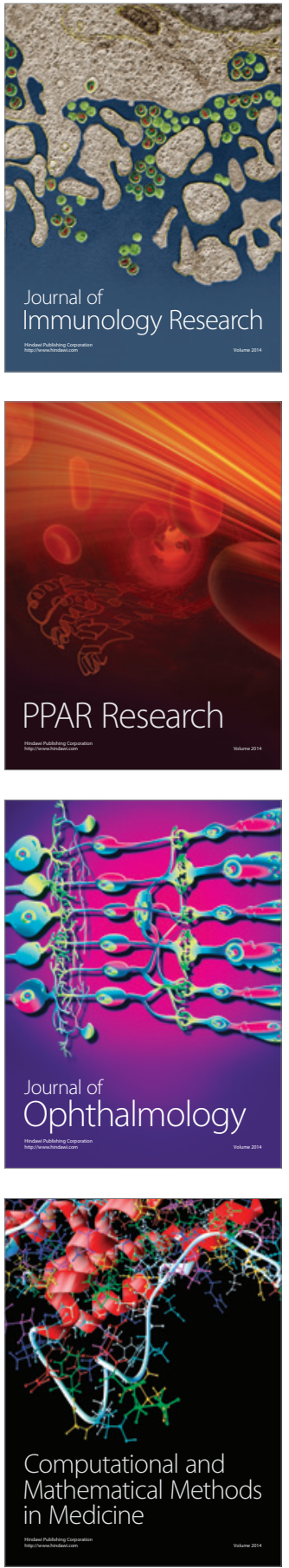

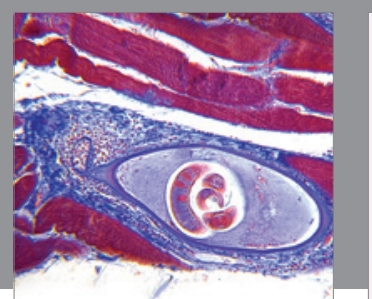

Gastroenterology Research and Practice

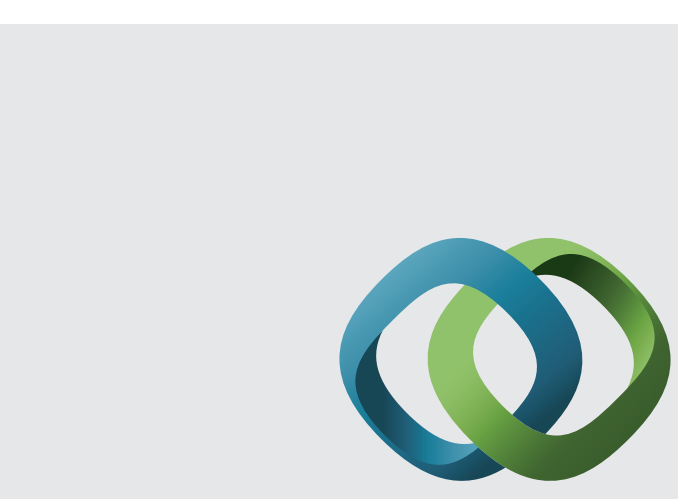

\section{Hindawi}

Submit your manuscripts at

http://www.hindawi.com
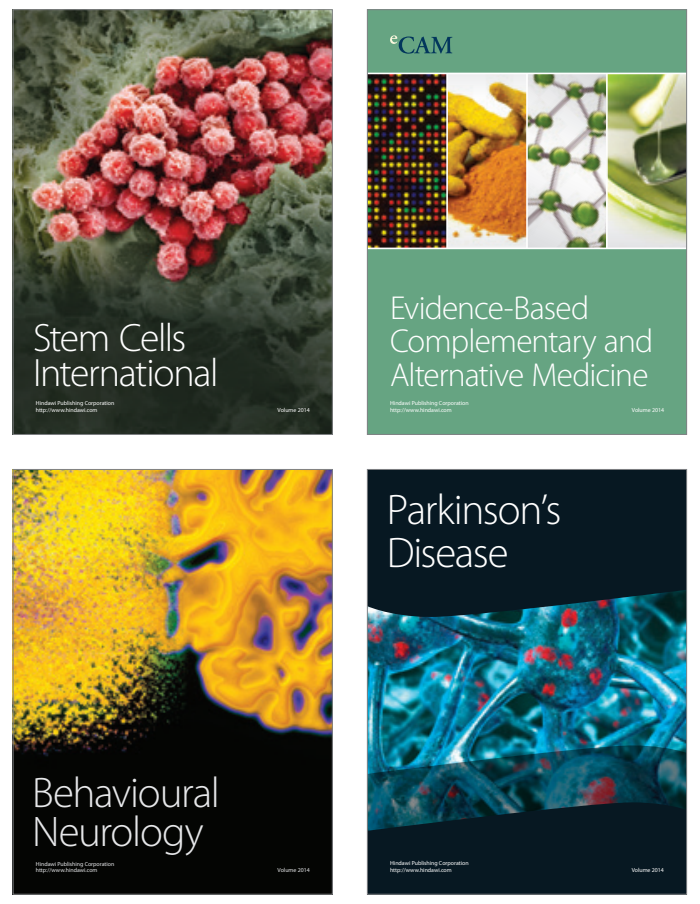
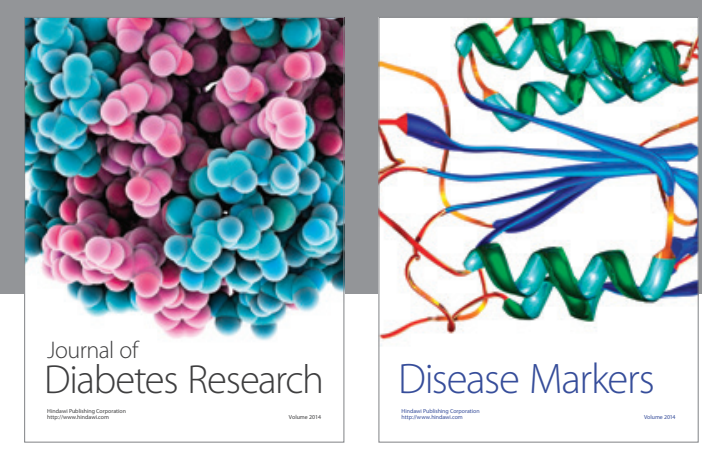

Disease Markers
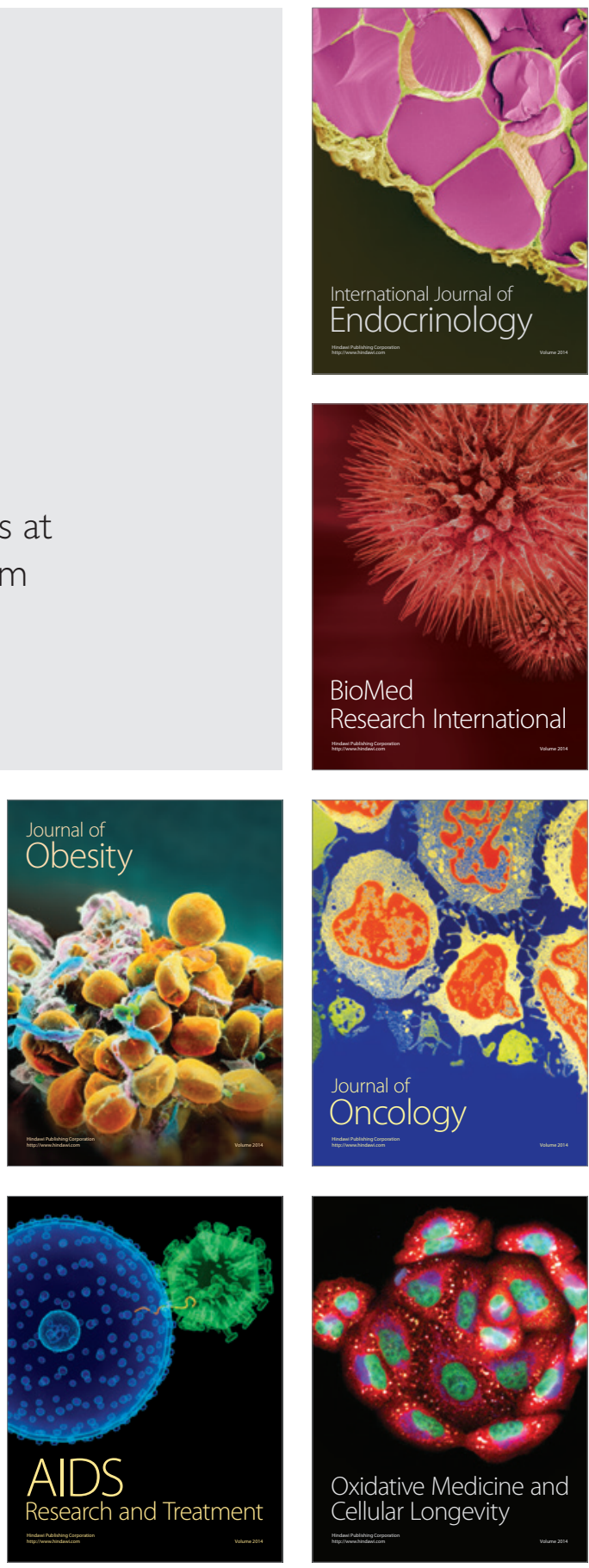